\title{
Fibrinogen Deficiency is Compatible with the Development of Atherosclerosis in Mice
}

\author{
Qing Xiao, ${ }^{\star}$ Mary Jo S. Danton, ${ }^{\star}$ David P. Witte, ${ }^{\ddagger}$ Mark C. Kowala, ${ }^{\S}$ Maria T. Valentine,${ }^{\S}$ and Jay L. Degen ${ }^{\star}$ \\ *Division of Developmental Biology and ${ }^{\ddagger}$ Division of Pathology, Children’s Hospital Research Foundation, Cincinnati, Ohio 45229; \\ ${ }^{\S}$ Division of Cardiovascular Drug Discovery, Bristol-Myers Squibb, Princeton, New Jersey 08543
}

\begin{abstract}
A critical role of the coagulation system in the development of atherosclerosis has been frequently postulated based on a variety of indirect observations, including the expression of procoagulants and fibrinolytic factors within atherosclerotic vessels, the presence of substantial amounts of fibrin(ogen) and fibrin degradation products within intimal lesions, the cellular infiltration and assimilation of mural thrombi into developing plaques, and the identification of high plasma fibrinogen (Fib) levels as an independent risk factor for the development of ischemic heart disease. To directly examine the role of fibrin(ogen) in atherogenesis, Fib-deficient mice were crossed to atherosclerosis-prone apolipoprotein $\mathrm{E}$ (apo E)-deficient mice. Both apo $\mathrm{E}^{-/-}$and apo $\mathrm{E}^{-/-} / \mathrm{Fib}^{-1-}$ mice developed lesions throughout the entire aortic tree, ranging in appearance from simple fatty streaks to complex fibrous plaques. Furthermore, remarkably little difference in lesion size and complexity was observed within the aortae of ageand gender-matched apo $\mathrm{E}^{-/-}$and apo $\mathrm{E}^{-/-} / \mathrm{Fib}^{-/-}$mice. These results indicate that the contribution of fibrin(ogen) to intimal mass and local cell adhesion, migration, and proliferation is not strictly required for the development of advanced atherosclerotic disease in mice with a severe defect in lipid metabolism. (J. Clin. Invest. 1998. 101:1184-1194.) Key words: atherosclerosis • fibrinogen - fibrin degradation products $\bullet$ apolipoprotein $\mathrm{E}$
\end{abstract}

\section{Introduction}

The prompt and concerted action of both specialized blood cells (platelets) and hemostatic factors enables vertebrate animals to withstand minor vascular injuries and survive severe vascular trauma. However, there is also an ominous danger associated with maintaining an effective hemostatic system: the formation of an occlusive blood clot within a cerebral or coronary vessel is a leading cause of morbidity and mortality worldwide. Interestingly, hemostatic factors may also contribute in more subtle ways to disease pathobiology. A substantial

Address correspondence to J.L. Degen, Ph.D., Children's Hospital Research Foundation, IDR-NRB Room 2025, 3333 Burnet Ave., Cincinnati, Ohio 45229. Phone: 513-636-4679; FAX: 513-636-4317; E-mail: degenjl@chmcc.org

Received for publication 11 August 1997 and accepted in revised form 7 January 1998.

J. Clin. Invest.

(C) The American Society for Clinical Investigation, Inc. 0021-9738/98/03/1184/11 \$2.00

Volume 101, Number 5, March 1998, 1184-1194

http://www.jci.org amount of indirect evidence suggests that hemostatic factors may play a critical role in the early progression of atherosclerotic disease that generally precedes and predisposes to debilitating or fatal arterial vaso-occlusion $(1,2)$.

Fibrin has been recognized as a major component of atherosclerotic lesions for over a century (3), and the location, level, molecular forms, and biological activities of fibrin(ogen) and fibrin(ogen) degradation products (FDPs) ${ }^{1}$ within atherosclerotic tissue have been well characterized $(4,5)$. Local fibrin(ogen) deposition and dissolution appear to be features of both early and advanced lesions, a finding that is consistent with the fact that the majority of the cell types participating in lesion formation (e.g., platelets, monocyte/macrophages, endothelial cells, and smooth muscle cells [SMCs]) are known to express a variety of procoagulants and/or fibrinolytic factors (6-9). A role of the coagulation system in atherosclerosis is also consistent with prospective epidemiological studies that have identified high plasma fibrinogen (Fib) concentration as an independent risk factor for ischemic heart disease $(10,11)$. Fibrinogen concentrations elevated just 20\% (one standard deviation) above the mean value of $2.9 \mathrm{mg} / \mathrm{ml}$ are associated with a 1.8-fold increase in the risk for ischemic heart disease over a 5 yr period (12). Relatively small changes in fibrinogen levels may be biologically significant in that kinetic models for fibrin generation in plasma predict that elevating plasma fibrinogen concentration by $20 \%$ would produce a similar percentage increase in the mass of fibrin clots (13). Hyperfibrinogenemia may also increase fibrin stability by reducing plasminogen binding to fibrin matrices (14). Therefore, one attractive explanation for the association of increased plasma fibrinogen concentration and ischemic heart disease is that larger and more persistent vascular thrombi may both accelerate atherosclerotic lesion development and increase the risk of vaso-occlusive events.

Accumulated fibrin within the vessel wall may influence lesion development by several potential mechanisms. First, fibrin might drive atherosclerosis by merely contributing to the total mass of extracellular matrix associated with developing intimal lesions. This contribution might be particularly significant following the fissure of unstable plaques and the subsequent formation and organization of mural thrombi (15). Second, fibrin(ogen) may serve as a key adhesion molecule, promoting the local capture or stabilization of circulating platelets and inflammatory cells $(16,17)$. Third, fibrin matrices may support the local proliferation and migration of inflammatory and smooth muscle cells $(18,19)$. Finally, plasmin-generated FDPs produced within atherosclerotic lesions may also be biologically significant in lesion progression. Specific FDPs extracted from human atherosclerotic tissue appear to have both

1. Abbreviations used in this paper: FDPs, fibrin degradation products; Fib, fibrinogen; SMCs, smooth muscle cells. 
mitogenic and angiogenic activities, properties that may contribute to atherogenesis in vivo (20-22).

The recent generation of gene-targeted mouse lines predisposed to severe atherosclerosis as a consequence of specific deficiencies in apolipoproteins or their receptors (23), coupled with the availability of mice with selected deficits in key hemostatic factors (24-26), has provided an opportunity to directly test the importance of specific coagulation and fibrinolytic factors in atherosclerosis in vivo. One mouse line that is particularly attractive for studying atherosclerosis is apolipoprotein $\mathrm{E}$ (apo E)-deficient mice. Even on a standard low fat diet, these mice develop widespread arterial lesions that progress with age from simple fatty streaks to complex fibrous plaques with many of the features of human atherosclerotic disease $(27,28)$. To directly determine the role of the key hemostatic factor, fibrin(ogen), in atherogenesis, we have compared the progression of vessel wall disease in apo $\mathrm{E}^{-1-}$ mice carrying plasma fibrinogen with apo $\mathrm{E}^{-1-}$ mice lacking fibrinogen. We report that total fibrin(ogen) deficiency is compatible with the development of advanced atherosclerotic disease in mice, and, at least in the context of a profound defect in lipid metabolism, the total absence of clotting function has surprisingly little impact on the rate of atherosclerotic lesion progression.

\section{Methods}

Mice. Fibrinogen (A $\alpha$ chain)-deficient mice (129/CF-1 genetic background; reference 24) were crossed to apo E-deficient mice (129/ $\mathrm{C} 57 \mathrm{Bl} / 6$; reference 29) to generate in first generation offspring $\mathrm{A}^{+/-}$ apo $\mathrm{E}^{+/-}$mice with hybrid 129/CF1/C57Bl/6 genetic background (ratio of 129:CF1:C57Bl/6 2:1:1). These animals were subsequently crossed to generate control, $\mathrm{Fib}^{-/-}$, apo $\mathrm{E}^{-1-}$, and apo $\mathrm{E}^{-/-} / \mathrm{Fib}^{-/-}$ mice with approximately the same mixture of genetic backgrounds. To control for any confounding influence of secondary genetic modifiers, comparative studies focused on littermate animals. The genotypes were determined by PCR analysis using tail or ear biopsy DNA. The wild-type apo $\mathrm{E}$ allele was detected using two primers from the 5 '-flanking region of the mouse apo E gene (apo E primer-1: $5^{\prime}$-GCTCCTGAAGGAACTGGAGCACGTCCCAGC-3'; apo E primer-2: 5'-GGTACTGGGCACTGAGAACCGCTCCTTCCC-3'; [30]), which generate a 220-bp product. The sequence of apo E primer-2 was deleted in the disrupted apo E allele (29). The targeted apo E allele was detected using apo E primer-1 (see above) and primer from the inserted Neo cassette (Neo primer-1: 5'-CATGAGAGCAGCCGATTGTCTGTTGTGCCC-3'), which generate a 570-bp product. The genotypes for the Fib gene were established as described (31). Mice of all genotypes were housed together and were fed a standard low fat mouse chow containing $6.5 \%$ fat (ether extraction) and $0.028 \%$ cholesterol (Formulab Diet 5008; Purina Mills, Inc., Richmond, IN).
Lipid analysis. Plasma lipid analyses were done using mice fasted for at least $6 \mathrm{~h}$. Cholesterol and triglycerides were measured enzymatically using a Boehringer Mannheim Hitachi 717 analyzer (Boehringer Mannheim Biochemicals, Indianapolis, IN). Lipid profile data were compared by the Mann-Whitney U test.

Histological analysis. Mice were killed under anesthesia and perfused through the left ventricle with phosphate buffered saline (PBS) followed by $10 \%$ neutral buffered formalin (Sigma Chemical Co., St. Louis, MO). For qualitative analyses, hearts and aortic arches were embedded in paraffin, sectioned at $4 \mu \mathrm{m}$ thickness, mounted on slides, and stained with either hematoxylin/eosin, elastic Van Gieson, or Gomori's trichrome. For quantitative analyses, tissues were processed and evaluated using a modification of the methods described by Paigen et al. (32) and Lawn et al. (33). Briefly, hearts were cut in half along a plane below the two atria and the top half was embedded in OCT compound (Miles Laboratories, Inc., Elkhart, IN). $10 \mu \mathrm{m}$ thick sections (cut perpendicular to the aorta) were prepared from the aortic sinus to the ascending aorta. The sections were mounted on slides, stained with oil red-O and hematoxylin, and the area of oil red$\mathrm{O}$-stained lesions were determined by an investigator unaware of animal genotype using a calibrated microscope eyepiece. Mean lesion area per section was calculated using the values obtained from five sections separated by $70 \mu \mathrm{m}$. To consistently score the same region within the aortae of individual animals, the first, most proximal section evaluated was at the point at which the aorta became rounded with the cusps of the valves barely discernible. Mean lesion areas from apo $\mathrm{E}^{-1-}$ and apo $\mathrm{E}^{-1-} / \mathrm{Fib}^{-/-}$mice were compared using a nonparametric median scores test.

Immunohistochemical analyses. Hearts were perfused with $4 \%$ paraformaldehyde in PBS and fixed for 4-8 h. Frozen or paraffin-embedded sections were collected onto Frost/Plus slides (Fisher Scientific Co., Fairlawn, NJ) and immunohistochemistry was performed with a Vector Elite ABC-Peroxidase kit (Vector Laboratories, Inc., Burlingame, CA) using 3-amino-9-ethyl-carbazole (AEC) as a chromogen (Biomeda Corp., Foster City, CA). Endothelial cells were stained with a rat anti-mouse PECAM monoclonal antibody (PharMingen, San Diego, CA), macrophages were stained with a rat anti-mouse Mac-2 monoclonal antibody (Boehringer Mannheim Biochemicals), and fibrin(ogen) was localized using rabbit anti-mouse fibrin(ogen) serum.

\section{Results}

Generation of mice with combined fibrinogen and apo $E$ deficiency. To generate mice with single $\left(\mathrm{Fib}^{-1-}\right.$; apo $\left.\mathrm{E}^{-/-}\right)$and combined (apo $\mathrm{E}^{-/-} / \mathrm{Fib}^{-/-}$) deficiencies in Fib and apo E, Fibdeficient mice were interbred with apo E-deficient mice. All progeny were normal in appearance at birth, but a fraction of the $\mathrm{Fib}^{-1-}$ mice developed spontaneous bleeding events in the neonatal period, a feature of fibrinogen-deficient mice reported previously (24). Mice surviving the neonatal period generally lived well into adulthood and displayed normal body

Table I. Cholesterol and Triglyceride Levels in Apo E- and Fib-deficient Mice

\begin{tabular}{|c|c|c|c|}
\hline Genotype & Total cholesterol $(\mathrm{mg} / \mathrm{dl})$ & HDL-cholesterol (mg/dl) & Triglyceride $(\mathrm{mg} / \mathrm{dl})^{*}$ \\
\hline $\mathrm{ApoE}^{+/-} / \mathrm{Fib}^{+/-}$ & $104 \pm 17(n=6)$ & $72 \pm 19(n=4)$ & $31(13-93, n=6)$ \\
\hline $\mathrm{ApoE}^{+/-} / \mathrm{Fib}^{-/-}$ & $117 \pm 35(n=5)$ & $95 \pm 44(n=5)$ & $20(16-146, n=5)$ \\
\hline $\mathrm{ApoE}^{-1-} / \mathrm{Fib}^{+/-}$ & $966 \pm 401^{\ddagger}(n=72)$ & $23 \pm 15^{\S}(n=71)$ & $91^{\pi}(15-635, n=72)$ \\
\hline $\mathrm{ApoE}^{-1-} / \mathrm{Fib}^{-/-}$ & $806 \pm 348^{ \pm \|}(n=68)$ & $27 \pm 17^{\S}(n=68)$ & $69(7-381, n=68)$ \\
\hline
\end{tabular}

Number of mice analyzed is indicated in parentheses. *Data were median value with range indicated in parentheses. ${ }^{\ddagger} P<0.001$ and ${ }^{\S} P<0.01$ as compared to apo $\mathrm{E}^{+-} / \mathrm{Fib}^{+/-}$and apo $\mathrm{E}^{+/-} / \mathrm{Fib}^{-/-}$mice. ${ }^{\|} P=0.0014$ as compared to apo $\mathrm{E}^{-/-} / \mathrm{Fib}^{+/-}$mice, total cholesterol levels in apo $\mathrm{E}^{-1-} / \mathrm{Fib}^{-/-}$mice are slightly, but significantly lower than that in apo $\mathrm{E}^{-/-} / \mathrm{Fib}^{+/-}$mice. ${ }^{\text {I }} P=0.03$ as compared to apo $\mathrm{E}^{+/-} / \mathrm{Fib}^{+/-}$mice. 

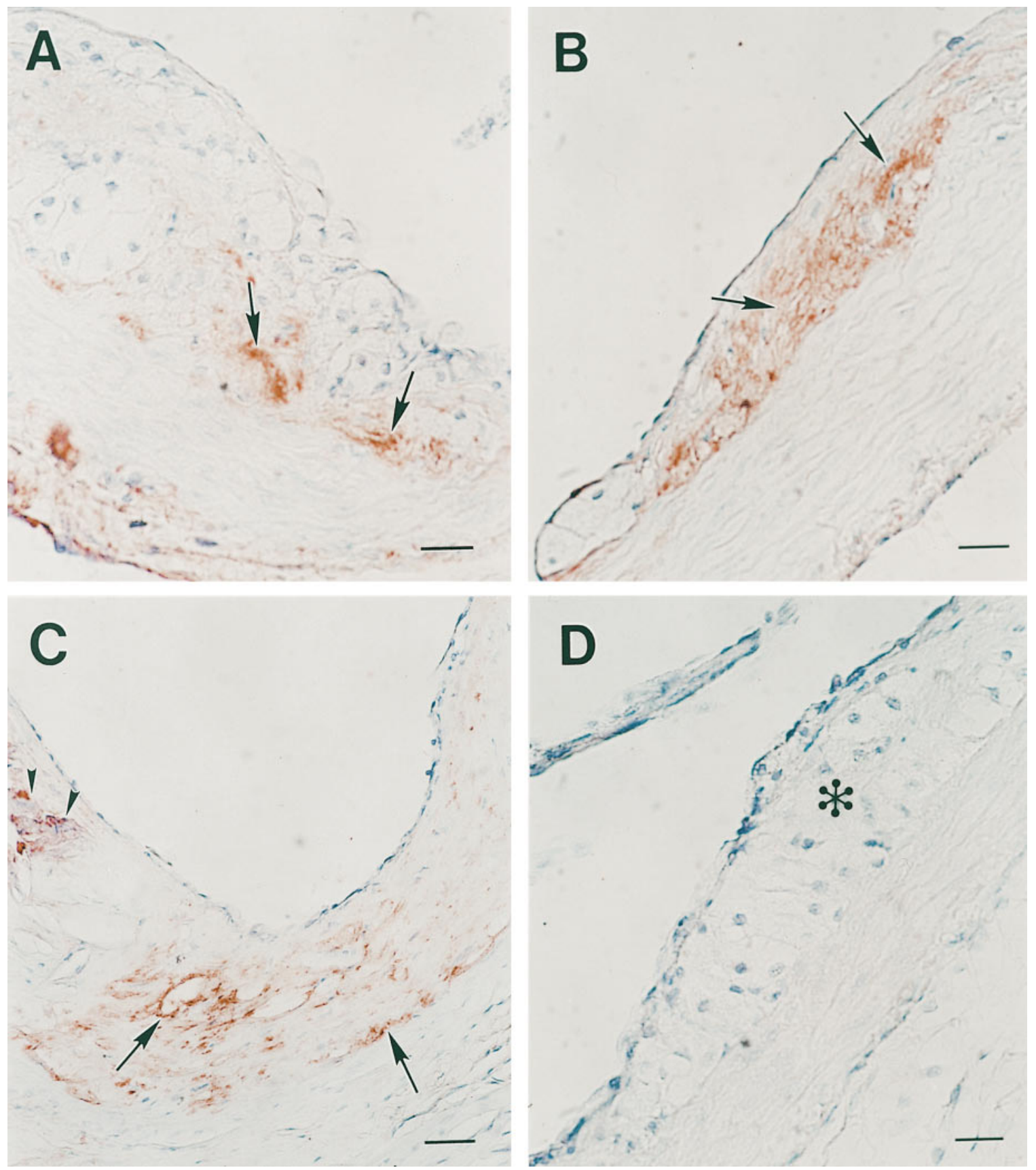

Figure 1. Fibrin(ogen) deposition in early intimal lesions. Sections from the proximal aorta of 26-wk-old $(A)$, 22-wk-old $(B)$, and 35-wk-old $(C)$ apo $\mathrm{E}^{-1-} / \mathrm{Fib}^{+/-}$mice immunostained for fibrin(ogen). Note fibrin(ogen) antigen (arrows) focused beneath a layer of foam cells in fatty streak lesion $(A)$, diffusely present within a fibrotic lesion $(B)$, and patchy within a necrotic zone $(C)$. A region of calcification is indicated by arrowheads in $C$. (D) Section from a 22-wk-old apo $\mathrm{E}^{-/-} / \mathrm{Fib}^{-/-}$mouse containing a foam cell-rich lesion (asterisk) that was immunostained in parallel with the sections in panels $A-C$. Note the distinct absence of fibrin(ogen) antigen within the lesion. Magnification bars $A, B$, and $D, 30 \mu \mathrm{m} ; C, 20 \mu \mathrm{m}$.

weights. Of $44 \mathrm{Fib}^{-/-}, 312$ apo $\mathrm{E}^{-/-}$and 257 apo $\mathrm{E}^{-/-} / \mathrm{Fib}^{-1-}$ mice that were monitored for survival between weaning and $26 \mathrm{wk}$ of age, $>95 \%$ of the animals survived to $10 \mathrm{wk}$ of age, regardless of genotype. However, only $70 \%$ of $\mathrm{Fib}^{-1-}$ and apo $\mathrm{E}^{-1-} / \mathrm{Fib}^{-1-}$ mice survived to $26 \mathrm{wk}$ of age as compared with $90 \%$ of apo $\mathrm{E}^{-1-}$ mice. The losses of $\mathrm{Fib}^{-1-}$ and apo $\mathrm{E}^{-/-} / \mathrm{Fib}^{-1-}$ mice were generally attributable to either spontaneous hemorrhagic events or pneumonitis.

Consistent with earlier studies $(29,34), 4-7$-month-old apo $\mathrm{E}^{-1-}$ mice developed severe hypercholesterolemia, elevated plasma triglycerides, and reduced HDL cholesterol (Table I). A similar plasma lipid profile was observed in apo $\mathrm{E}^{-/-}$mice that carry and lack plasma fibrinogen (Table I). Gender was not found to be a significant variable, but total plasma cholesterol and triglyceride levels tended to be higher in males (data not shown). Fibrinogen deficiency alone had no appreciable impact on lipid profile relative to control mice.

Fibrin(ogen) deposition within atherosclerotic lesions of apo $E^{-/-}$mice. Consistent with the well-documented presence of fibrin(ogen) and fibrin degradation products within 

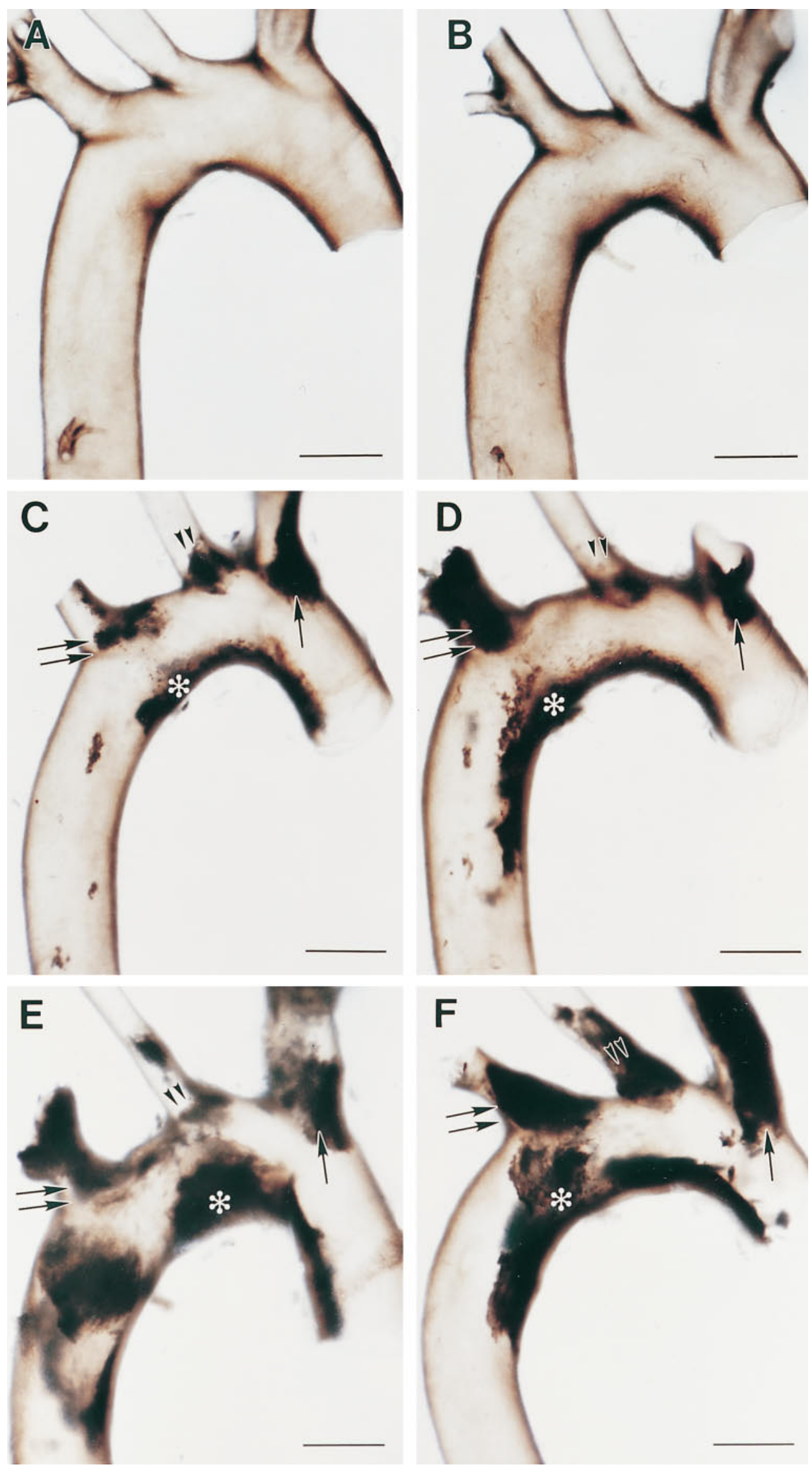

Figure 2. Gross appearance and ranking of lesions in the aortic arches of apo E- and Fib-deficient mice. Brightfield view of the aortic arches collected from 32-wk-old $\mathrm{Fib}^{-1-}(A)$ and 54-wk-old control $(B)$ mice. Representative views of aortic arches collected from apo $\mathrm{E}^{-1-} / \mathrm{Fib}^{-1-}$ $(C$ and $E)$ and apo $\mathrm{E}^{-1-}(D$ and $F)$ mice at $22(C$ and $D)$ and $26(E$ and $F)$ wk of age. Note the dark-appearing atherosclerotic lesions in the lesser curvature of the arch (aster$i s k$ ), the branch points of the brachiocephalic trunk (single arrow), left common carotid (double arrowheads), and left subclavian (double arrows). The lesions appear as opaque, cream-colored deposits under darkfield. The vessels in $A$ and $B, C$ and $D$, and $E$ and $F$ were scored 0,2 , and 4 , respectively, with the ranking system employed (see text and Fig. 3). Magnification bars, $1 \mathrm{~mm}$. 
human atherosclerotic lesions, fibrin(ogen) was easily detected immunologically within atherosclerotic tissue sections prepared from apo $\mathrm{E}^{-/-}$mice (Fig. 1). Fibrin(ogen) was detected within various types of lesions including foam cell-rich fatty streaks, fibrous lesions, and advanced plaques (Fig. $1, A-C$ ) of apo $\mathrm{E}^{-1-}$ mice. In early lesions, fibrin(ogen)-rich matrices were observed at the base of the neointima, possibly contributing to cell adhesion (Fig. $1 A$ ). In more complicated fibrous lesions, fibrin(ogen) was widely distributed within the fibrous intimal tissues, but little staining was evident within the adjacent media layer (Fig. 1, $B$ and $C$ ). Similarly, little or no immunoreactive material was detected within the vessel walls of apo E-expressing mice or normal appearing vessels of apo $\mathrm{E}^{-/-}$ mice (data not shown). Finally, consistent with the null phenotype of $\mathrm{Fib}^{-1-}$ mice (24), no fibrinogen-related antigen could be detected within lesions of apo $\mathrm{E}^{-/-} / \mathrm{Fib}^{-1-}$ mice (Fig. $1 D$ ).

Effect of fibrinogen deficiency on atherosclerosis in the aortic arch. To initially determine the impact of fibrin(ogen) deficiency on the development and progression of atherosclerosis, whole mounts of the aortic arches collected from control, $\mathrm{Fib}^{-/-}$, apo $\mathrm{E}^{-/-}$, and apo $\mathrm{E}^{-/-} / \mathrm{Fib}^{-/-}$mice were examined microscopically (Fig. 2) and scored for lesion severity (see below). No visible lesions were seen in the arches of forty-one 27to 90 -wk-old control mice and eighteen 18- to 56-week-old $\mathrm{Fib}^{-1-}$ mice examined (see representative data in Fig. 2, $A$ and $B)$. However, 45 of 48 apo $\mathrm{E}^{-1-} / \mathrm{Fib}^{-/-}$mice and all 54 apo $\mathrm{E}^{-1-}$ mice from 22 to $31 \mathrm{wk}$ of age were found to have obvious aortic lesions (see representative data in Fig. 2, $C-F$ ). The lesions were particularly prominent at previously identified predilection sites (27), including the lesser curvature of the arch and the carotid branch points. Furthermore, the lesions appeared to be more extensive as a function of age (compare Fig. 2, $C$ and $D$ with $E$ and $F$ ). To systematically compare the lesions in apo $\mathrm{E}^{-/-}$and apo $\mathrm{E}^{-/-} / \mathrm{Fib}^{-/-}$mice, the gross appearance of lesions was ranked by an investigator unaware of animal genotype using an arbitrary scoring system in which the absence of lesions was graded as 0 (for examples, see Fig. 2, $A$ and $B$ ), extensive lesions encompassing all three carotid branch points and the entire lesser curvature were graded as four (for examples, see Fig. 2, $E$ and $F$ ), and the severity of intermediate lesions was graded from one to three. Analysis of the data (shown in Fig. 3) using a nonparametric median scores test indicated that lesions were slightly, but significantly $(P<0.04)$, less extensive in 22 -wk-old apo $\mathrm{E}^{-1-} / \mathrm{Fib}^{-1-}$ mice relative to apo $\mathrm{E}^{-/-}$controls. However, the score distributions were not significantly different at either 26 or 31 wk of age. Therefore, based on the gross appearance of aortae, fibrinogen deficiency results in only a modest reduction in the pace of lesion development in apo $\mathrm{E}^{-1-}$ mice, and widespread vascular disease ultimately occurs despite the absence of clotting function.

Microscopic appearance of lesions within the proximal aortae of apo $E^{-/-}$and apo $E^{-/-} / F_{i b} b^{-/}$mice. The proximal aorta has been a major focus for qualitative and quantitative studies of atherosclerosis in the mouse because the region is particularly prone to intimal lesion development and the cusps of the valves provide a useful positional cue in comparative studies of sectioned tissue. To qualitatively compare lesions in the proximal aortae, serial sections were prepared in order to survey the aortic sinus and ascending aorta from ten 41- to 68-wk-old control mice, seventeen 18- to 56-wk-old $\mathrm{Fib}^{-1-}$ mice, nineteen 22to 31-wk-old apo $\mathrm{E}^{-1-}$ mice, and thirteen 22- to 31-wk-old apo $\mathrm{E}^{-1-} / \mathrm{Fib}^{-/-}$mice (every apo $\mathrm{E}^{-/-} / \mathrm{Fib}^{-1-}$ animal was evaluated with at least one apo $\mathrm{E}^{-1-}$ littermate). Lesions were not observed in any control mice or Fib ${ }^{-1-}$ mice using hematoxylin/ eosin, trichrome, or van Gieson's stain, whereas intimal lesions were uniformly detected in both apo $\mathrm{E}^{-/-}$and apo $\mathrm{E}^{-/-} / \mathrm{Fib}^{-/-}$ mice using all three staining systems (Figs. 4 and 5). The morphological features of individual lesions varied from simple fatty streaks to complex fibrous plaques, but a similar panorama of lesions was observed in both apo $\mathrm{E}^{-/-}$and apo $\mathrm{E}^{-1-} /$ $\mathrm{Fib}^{-1-}$ mice (Figs. 4 and 5). At 22 wk of age, the lesions were primarily fatty streaks (representative data in Fig. 4, $C$ and $D$ ). The lipid-laden foam cells within the intima were generally macrophage-derived based on their staining with a Mac-2 monoclonal antibody (data not shown). In 26- and 31-wk-old apo $\mathrm{E}^{-1-}$ and apo $\mathrm{E}^{-1-} / \mathrm{Fib}^{-/-}$mice, the lesions progressed to mainly fibrofatty lesions and advanced fibrous plaques (Fig. 4, $E-J)$. These lesions typically showed extensive accumulation of collagen and elastic fibers in the intima based on trichrome

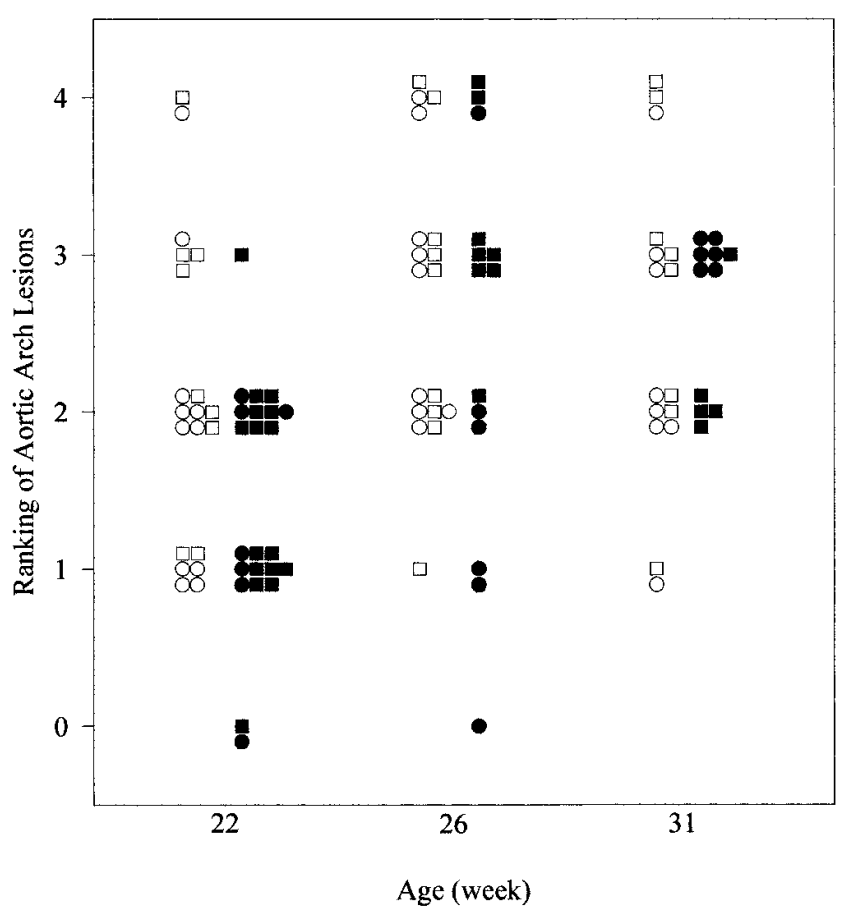

Figure 3. Comparison of lesion development in the aortic arch of apo $\mathrm{E}^{-1-}$ and apo $\mathrm{E}^{-1-} / \mathrm{Fib}^{-1-}$ mice. The lesion severity of apo $\mathrm{E}^{-1-}$ (open symbols) and apo $\mathrm{E}^{-1-} / \mathrm{Fib}^{-1-}$ mice (closed symbols) at 22, 26, and 31 wks of age was scored according to the ranking system described in the text. Whole number scores were assigned between 0 (absence of lesions) and 4 (extensive lesions encompassing all carotid branch points and the entire lesser curvature). Males and females are indicated with squares and circles, respectively. Mice were primarily evaluated with littermate controls: specifically, of 23 apo $\mathrm{E}^{-1-} / \mathrm{Fib}^{-1-}$ mice analyzed at $22 \mathrm{wk}$ of age, 19 were evaluated with at least one apo $\mathrm{E}^{-1-}$ littermate; of 14 apo $\mathrm{E}^{-1-} / \mathrm{Fib}^{-1-}$ mice analyzed at $26 \mathrm{wk}$ of age, 12 were evaluated with at least one apo $\mathrm{E}^{-1-}$ littermate; of 11 apo $\mathrm{E}^{-1-}$ $\mathrm{Fib}^{-1-}$ mice analyzed at $31 \mathrm{wk}$ of age, 10 were evaluated with at least one apo $\mathrm{E}^{-l-}$ littermate. Statistical comparisons of the distributions using a nonparametric median scores test indicated that the lesions were slightly, but significantly $(P<0.04)$, less extensive in apo $\mathrm{E}^{-1-}$ $\mathrm{Fib}^{-1-}$ mice relative to apo $\mathrm{E}^{-1-}$ mice at $22 \mathrm{wk}$ of age. No significant difference was apparent between genotypes at $26 \mathrm{wk}(P=0.96)$ and $31 \mathrm{wk}(P=0.14)$ of age. Gender was not a significant variable at all ages examined. 

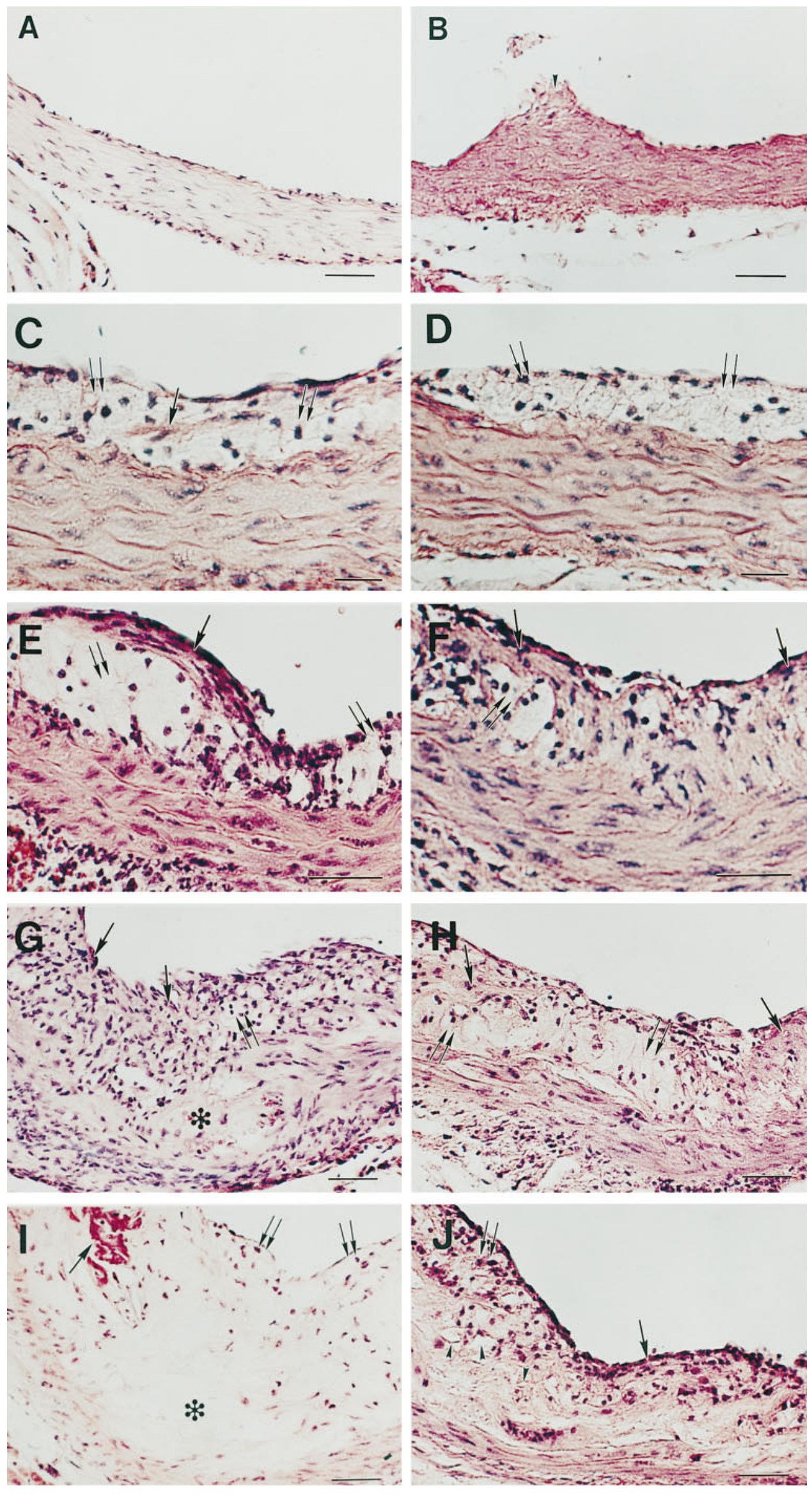

Figure 4. Representative sections from the proximal aorta of control $(A), \mathrm{Fib}^{-/-}(B)$, apo $\mathrm{E}^{-/-}(C, E, G$, and $I)$, and apo $\mathrm{E}^{-l-} / \mathrm{Fib}^{-/-}(D, F, H$, and $J$ ) mice stained with hematoxylin/eosin. $(A)$ Normal appearing vessel in a 54-wk-old control mouse. $(B)$ Normal appearing vessel in a 31-wkold $\mathrm{Fib}^{-1-}$ mouse in the vicinity of a valve cusp (arrowhead). Typical foam cell-rich (double arrows) fatty streak in 22-wk-old apo $\mathrm{E}^{-1-}(C)$ and apo $\mathrm{E}^{-l-} / \mathrm{Fib}^{-1-}(D)$ mice. The single arrow in $C$ indicates a small amount of intimal fibrous tissue. Fibrofatty lesions in 26-wk-old apo $\mathrm{E}^{-/-}$( $E$ and $G)$ and apo $\mathrm{E}^{-/-} / \mathrm{Fib}^{-1-}(F$ and $H)$ mice showing foam cells (double arrows) and substantial fibrous tissues (single arrows). A necrotic zone adjacent to disorganized or disrupted medial layer is indicated by an asterisk in $G$. Advanced lesions in 31-wkold apo $\mathrm{E}^{-/-}(I)$ and apo $\mathrm{E}^{-/-} / \mathrm{Fib}^{-/}$ $(J)$ mice. Areas highlighted by an asterisk, single arrow, and double arrows in $I$ indicate acellular core, calcification, and foam cells, respectively. Areas highlighted by single arrow, arrowheads, and double arrows in $J$ indicate fibrous tissue, cholesterol clefts, and foam cells, respectively. Magnification bars in $A$, $B$, and $E-J, 50 \mu \mathrm{m} ; C$ and $D, 25 \mu \mathrm{m}$. 

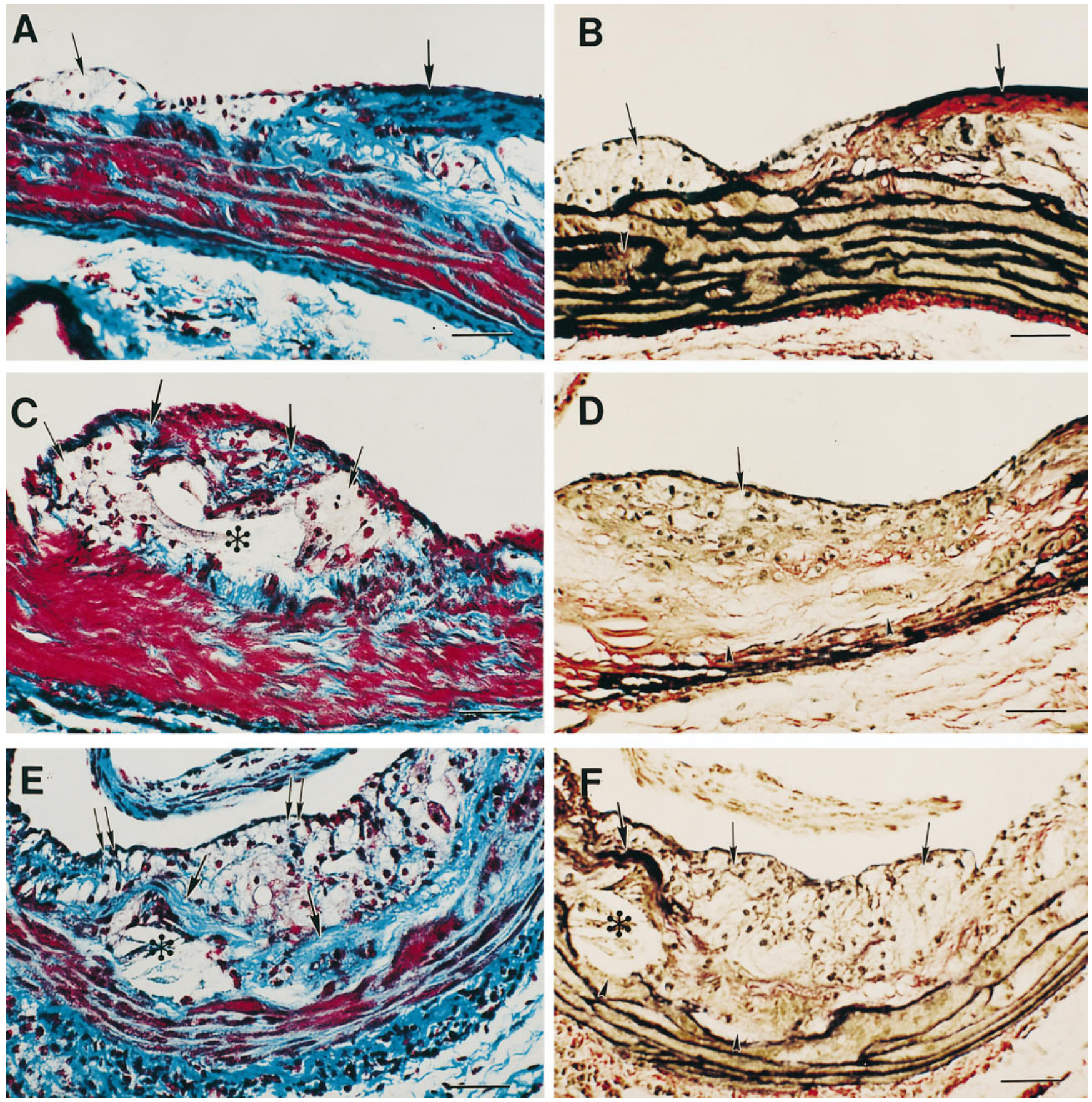

Figure 5. Histological staining of collagen and elastic fibers within proximal aortae of 31-wk-old apo $\mathrm{E}^{-l-}$ and apo $\mathrm{E}^{-1-} / \mathrm{Fib}^{-1-}$ mice. Collagen and elastic fibers were stained with Gomori's trichrome $(A, C$, and $E)$ and elastic van Gieson's stain $(B, D$, and $F)$, respectively. $(A-D)$ Representative sections containing fibrofatty lesions in apo $\mathrm{E}^{-1-} / \mathrm{Fib}^{-1-}$ mice. Note the substantial collagen deposition within the intima (intensely blue-staining material indicated by large arrows in $A$ and $C$ ). Also note elastic fiber deposition in the intima (intensely black-staining material highlighted by large arrow in $B$ ) and elastic fiber thinning and disruption in the medial layers (arrowheads in $B$ and $D)$. $(A-D)$ Small arrows indicate foam cells. The asterisk in $C$ indicates large, unstained cholesterol clefts. $\left(E\right.$ and $F$ ) Representative fibrofatty lesion in an apo $\mathrm{E}^{-/-}$mouse showing similar features to that seen in apo $\mathrm{E}^{-1-} / \mathrm{Fib}^{-1-}$ mice, including collagen (large arrows in $E$ ) and elastic fiber (large arrow in $F$ ) deposition in intima, and medial elastic fiber distortion and thinning (arrowheads in $F$ ). ( $E$ and $F$ ) The asterisks and small arrows indicate cholesterol clefts and foam cells, respectively. Magnification bars, $50 \mu \mathrm{m}$.

and van Gieson staining (Fig. 5), and often displayed distortion or disruption of medial elastic fibers in the most advanced lesions (Fig. 5, $B, D$, and $F$ ). Advanced lesions contained cholesterol clefts and central necrotic cores, and were surrounded or capped by a layer of SMCs (Fig. 4, E-J, and Fig. 5), regardless of genotype. Based on immunohistochemical staining with a PECAM-specific antibody, an intact monolayer of endothelial cells covered the luminal surface of fatty-streak, fibrofatty, and fibrous lesions in both apo $\mathrm{E}^{-/-}$and apo $\mathrm{E}^{-/-} / \mathrm{Fib}^{-1-}$ mice (data not shown). Plaque fissure and mural thrombus forma- 

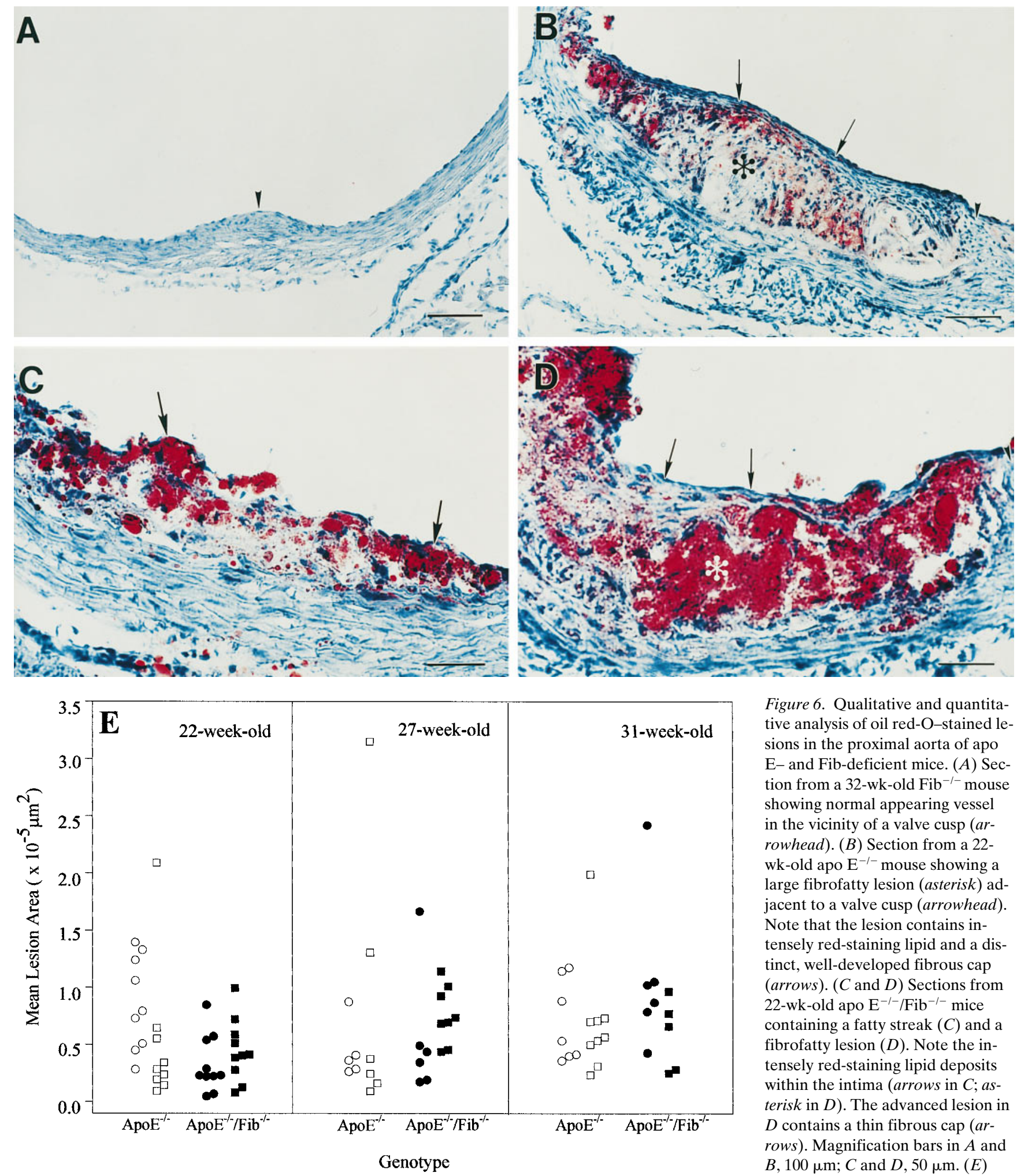

Figure 6. Qualitative and quantitative analysis of oil red-O-stained lesions in the proximal aorta of apo $\mathrm{E}$ - and Fib-deficient mice. (A) Section from a 32-wk-old $\mathrm{Fib}^{-1-}$ mouse showing normal appearing vessel in the vicinity of a valve cusp ( $a r$ rowhead). (B) Section from a 22wk-old apo $\mathrm{E}^{-/-}$mouse showing a large fibrofatty lesion (asterisk) adjacent to a valve cusp (arrowhead). Note that the lesion contains intensely red-staining lipid and a distinct, well-developed fibrous cap (arrows). ( $C$ and $D)$ Sections from 22-wk-old apo $\mathrm{E}^{-1-} / \mathrm{Fib}^{-1-}$ mice containing a fatty streak $(C)$ and a fibrofatty lesion $(D)$. Note the intensely red-staining lipid deposits within the intima (arrows in $C$; asterisk in $D$ ). The advanced lesion in $D$ contains a thin fibrous cap ( $a r$ rows). Magnification bars in $A$ and $B, 100 \mu \mathrm{m} ; C$ and $D, 50 \mu \mathrm{m}$. (E) Mean cross-sectional lesion areas in the proximal aortas of apo $\mathrm{E}^{-1-}$ mice (open symbols) and apo $\mathrm{E}^{-1-} / \mathrm{Fib}^{-1-}$ mice (closed symbols) at 22, 27, and 31 wk of age. Male and female mice are illustrated with squares and circles, respectively. Mice were primarily evaluated with littermate controls: specifically, of 20 apo $\mathrm{E}^{-/-} /$ $\mathrm{Fib}^{-1-}$ mice analyzed at $22 \mathrm{wk}$ of age, 19 were evaluated with at least one apo $\mathrm{E}^{-1-}$ littermate; all 14 apo $\mathrm{E}^{-/-} / \mathrm{Fib}^{-/-}$mice analyzed at $26 \mathrm{wk}$ of age were evaluated with at least one apo $\mathrm{E}^{-/-}$littermate; of 11 apo $\mathrm{E}^{-1-} / \mathrm{Fib}^{-/-}$mice analyzed at $31 \mathrm{wk}$ of age, 10 were evaluated with at least one apo $\mathrm{E}^{-/-}$littermate. Based on a nonparametric median scores test, the distribution of mean lesions areas for apo $\mathrm{E}^{-/-} / \mathrm{Fib}^{-/-}$and apo $\mathrm{E}^{-/-}$mice was not significantly different at $22(P=0.21), 26(P=0.12)$, or $31(P=0.19)$ wk of age. 
tion were not evident in any lesion examined in this study. Therefore, taken together, the only obvious qualitative distinction between atherosclerotic lesions in apo $\mathrm{E}^{-/-}$and apo $\mathrm{E}^{-/-}$ $\mathrm{Fib}^{-1-}$ mice was the distinct absence of fibrin(ogen) deposits in the latter.

Quantitative analysis of lesions within the proximal aortae of apo $E^{-/-}$and apo $E^{-/-} / \mathrm{Fib}^{-/-}$mice. To quantitatively examine the impact of fibrinogen deficiency on the development of atherosclerotic lesions in the proximal aorta, mean lesion areas were measured in oil red-O-stained tissue sections following the well-established experimental approach described by Paigen et al. (32). Consistent with earlier histological analyses of proximal aortae, oil red-O staining revealed no lesions within proximal aortae of 41 control mice $(27-90 \mathrm{wk}$ of age) or $18 \mathrm{Fib}^{-/-}$mice (18-56 wk of age) (see representative data in Fig. 6 A). However, oil red-O-stainable lesions were observed in virtually all of ninety 22 - to 31 -wk old apo $\mathrm{E}^{-/-}$and apo $\mathrm{E}^{-/-} /$ $\mathrm{Fib}^{-1-}$ mice examined (Fig. 6). Quantitative analyses of the mean lesion areas in the proximal aortae of apo $\mathrm{E}^{-/-}$and apo $\mathrm{E}^{-1-} / \mathrm{Fib}^{-1-}$ mice indicated that lesion areas varied considerably between individuals within a genotype and age group, but the lesion area distributions were not significantly different between genotypes at 22,27 , or $31 \mathrm{wk}$ of age $(P=0.12-0.21)$ (Fig. $6 E$ ). Furthermore, no significant difference was found between genotypes in paired analyses, whereby the lesion areas were compared in apo $\mathrm{E}^{-1-}$ and apo $\mathrm{E}^{-1-} / \mathrm{Fib}^{-1-}$ littermate sets at $22(n=19$ pairs; $P>0.1), 27(n=14$ pairs; $P>0.7)$, and 31 ( $n=10$ pairs; $P>0.4)$ wk of age. Thus, based on quantitative measurements in the proximal aortae, fibrinogen deficiency results in no marked diminution of atherosclerotic lesion development.

\section{Discussion}

These studies show that a total absence of fibrin(ogen) is compatible with the development and progression of atherosclerosis in hypercholesterolemic, apo $\mathrm{E}^{-/-}$mice. Like apo $\mathrm{E}^{-/-}$ mice, apo $\mathrm{E}^{-1-} / \mathrm{Fib}^{-1-}$ mice maintained on a standard low fat diet developed intimal lesions throughout the aortic tree, including the proximal aorta, lesser curvature of the arch, and arterial branch points. In addition, the general pattern of lesion formation was similar in both apo $\mathrm{E}^{-1-}$ and apo $\mathrm{E}^{-1-} / \mathrm{Fib}^{-/-}$ mice, with fatty streak lesions predominating in the aortae of young animals and increasingly complex fibrous plaques in the aortae of older mice. Finally, aside from the distinct absence of immunologically-detectable fibrin(ogen) deposits, lesions of comparable complexity in apo $\mathrm{E}^{-1-} / \mathrm{Fib}^{-1-}$ and apo $\mathrm{E}^{-1-}$ mice were histologically indistinguishable. Studies focusing on the proximal aortae of young apo $\mathrm{E}^{-/-} / \mathrm{Fib}^{-/-}$mice suggest that fibrinogen deficiency has little, if any, impact on the rate of lesion development. Furthermore, evaluated qualitatively and quantitatively, the ultimate outcome is not appreciably different in the presence and absence of fibrin(ogen). These findings provide direct evidence that fibrin(ogen), a consistently recognized feature of atherosclerotic lesions, is not strictly required for lesion progression in the context of a significant disorder in lipid metabolism.

The gene knockout approach is highly informative in defining whether a factor is obligatory for a biological process. Thus, it is clear from these studies that fibrin(ogen) is not obligatory for the development of atherosclerotic disease. However, when a factor is shown to be not required for a pro- cess, the approach neither excludes the participation of the factor in that process nor excludes an important role of the factor under specific conditions, such as in the absence of a compensatory factor or in the presence of a second genetic or environmental challenge. Thus, it is important to recognize that the finding that fibrinogen is dispensable for atherogenesis in apo $\mathrm{E}^{-/-}$mice by no means indicates that fibrin(ogen) is unimportant in vessel wall disease, particularly in other distinct biological settings (e.g., in mice with other genetic disorders [see below] or in human subjects). Indeed, available data in other animals models and human patients strongly support the view that fibrin(ogen) is very important in vessel wall disease and may contribute to lesion progression by many mechanisms. The distinct features of lesion development in mice in general, and the apo E knockout mice in particular, may obscure and minimize the potential contribution of fibrin(ogen) to atherogenesis. One obvious difference between mice and humans is that mice, as a species, are remarkably resistant to atherosclerosis, with only profound genetic or dietary challenges resulting in appreciable atherosclerotic disease. Apo $\mathrm{E}^{-1-}$ mice develop severe atherosclerosis at a young age, but their plasma cholesterol levels are nearly an order of magnitude higher than those observed in wild-type mice or normal human subjects. Therefore, in the context of such an extremely lipid-driven model of atherosclerosis, the contribution of local fibrin(ogen) deposition to lesion development might be relatively low. In contrast, in the context of human atherosclerosis, which generally develops over decades and in the setting of much lower plasma cholesterol levels, the specific contribution of fibrin(ogen) to lesion development may be pronounced. In this regard, a useful extension of these studies would be to explore the role of fibrinogen in atherogenesis in mouse lines that develop disease over an extended time frame and in the context of plasma lipid profiles closer to that seen in human subjects, such as LDL receptor-deficient mice (35).

There are several other obvious distinctions between mice and humans that might result in differences in the relative importance of fibrin(ogen) in the progression of vessel wall disease in the two species. For example, differences in the overall size and local hemodynamics of the arteries affected may be determining factors. In addition, there are clear differences in both plasma lipoproteins and lipid metabolism, such as the absence of $L p(a)$ in mice $(33,36)$. The difference in $L p(a)$ is particularly intriguing in that high levels of $\mathrm{Lp}(\mathrm{a})$ in humans are an established risk factor for ischemic heart disease, and one of the component subunits, apo (a), is known to both bind fibrin and attenuate plasminogen activation (37-40).

Perhaps the most significant distinction between mouse and human atherosclerotic disease that should be considered in attempting to reconcile the findings of this paper with available evidence supporting an important role of fibrin(ogen) in human disease is that mural thrombus formation secondary to plaque fissure is a common feature of human disease, whereas these events have never been documented in mouse models of atherogenesis. This distinction is particularly notable in that the formation of clinically-silent mural thrombi may be a major driving force in the progression of human vessel wall disease. Indeed, human atherosclerotic lesions often have a layered appearance suggestive of multiple cycles of plaque fissure, mural thrombus formation, and cellular organization by inflammatory and SMCs $(2,15)$. The absence of these cycles in mice genetically predisposed to atherosclerosis is likely 
to minimize the potential contribution of fibrin matrix deposition to lesion progression.

Although fibrin(ogen) does not appear to be a powerful modifier of atheroslerotic disease in unchallenged apo $\mathrm{E}^{-/-}$ mice, a number of secondary challenges in these animals could conceivably render the rate of atherogenesis highly-dependent on fibrin(ogen). For example, a dramatic local or systemic alteration in the hemostatic balance either favoring local fibrin deposition or impeding fibrinolysis could result in an acceleration of atherosclerosis that is mechanistically tied to fibrin(ogen). In this regard, we have shown recently that loss of a key fibrinolytic factor, plasminogen, greatly accelerates the formation of intimal lesions in apo E-deficient mice, whereas plasminogen deficiency alone does not cause appreciable atherosclerosis (41). However, while fibrin(ogen) is conspicuous within both early and advanced lesions of apo $\mathrm{E}^{-/-} / \mathrm{Plg}^{-/-}$ mice, presently there is no direct evidence that the aggravating effect of plasminogen deficiency on atherosclerosis is related to fibrin(ogen) and impaired fibrinolysis. Indeed, a second mechanism whereby plasminogen deficiency might promote atherosclerosis is through the loss of plasmin-mediated TGF- $\beta$ activation in the vessel wall (42-44). Comparative studies of atherosclerosis in apo $\mathrm{E}^{-/-}$mice with single and combined deficits in plasminogen and fibrinogen will be highly instructive in defining the role of fibrin(ogen) in the acceleration of lesion progression in apo $\mathrm{E}^{-1-} / \mathrm{Plg}^{-/-}$mice.

Vascular injury is another context where fibrin(ogen) may be shown to be important in neointima formation. Repetitive or chronic injury and inflammation leading to recurring or persistent fibrin in the vessel wall may strongly favor vascular stenosis by supporting the local capture of circulating platelets and inflammatory cells, and/or promoting the proliferation and migration of SMC and other cells. This hypothesis can be directly tested by exploring the impact of the loss of fibrinogen, or other hemostatic factors, on vascular repair and neointima development after surgical challenges or chronic inflammatory injuries (45-47).

\section{Acknowledgments}

We gratefully acknowledge the thoughtful advice of Thomas Bugge, Kenn Holmbäck, Angela Drew, and Keith Kombrinck. We thank Avinne Overton, A. Katherine Ware, Kathy Saalfeld, Pamela Groen, and Bhavani Pathak for their technical assistance. We also thank Susan Wert and Sherri Profitt for their help with histological and morphometric analyses.

This work was supported by grants from the National Institutes of Health (HL47826). Additional support was provided by the National American Heart Association (with funds contributed by the AHA Ohio affiliate) (92-1103). This study was done during the tenure of an Established Investigatorship (J.L. Degen) from the American Heart Association (93002570).

\section{References}

1. Schwartz, C.J., A.J. Valente, J.L. Kelley, E.A. Sprague, and E.H. Edwards. 1988. Thrombosis and the development of atherosclerosis: Rokitansky revisited. Semin. Thromb. Hemostasis. 14:189-195.

2. Fuster, V., L. Badimon, J.J. Badimon, and J.H. Chesebro. 1992. The pathogenesis of coronary artery disease and the acute coronary syndromes. $N$. Engl. J. Med. 326:242-250.

3. von Rokitansky, C. 1852. Abnormal conditions of the arteries. In A Manual of Pathological Anatomy. Sydenham Society, London. 261-275.

4. Bini, A., and B.J. Kudryk. 1995. Fibrinogen in human atherosclerosis. Ann. NY Acad. Sci. 748:461-471.
5. Bini, A., J.J. Fenoglio, Jr., R. Mesa-Tejada, B. Kudryk, and K.L. Kaplan. 1989. Identification and distribution of fibrinogen, fibrin, and fibrin(ogen) degradation products in atherosclerosis. Use of monoclonal antibodies. Arteriosclerosis. 9:109-121.

6. Wilcox, J.N., K.M. Smith, S.M. Schwartz, and D. Gordon. 1989. Localization of tissue factor in the normal vessel wall and in the atherosclerotic plaque. Proc. Natl. Acad. Sci. USA. 86:2839-2843.

7. Schneiderman, J., M.S. Sawdey, M.R. Keeton, G.M. Bordin, E.F. Bernstein, R.B. Dilley, and D.J. Loskutoff. 1992. Increased type 1 plasminogen activator inhibitor gene expression in atherosclerotic human arteries. Proc. Natl. Acad. Sci. USA. 89:6998-7002.

8. Lupu, F., D.A. Heim, F. Bachmann, M. Hurni, V.V. Kakkar, and E.K. Kruithof. 1995. Plasminogen activator expression in human atherosclerotic lesions. Arterioscler. Thromb. Vasc. Biol. 15:1444-1455.

9. Robbie, L.A., N.A. Booth, A.J. Brown, and B. Bennett. 1996. Inhibitors of fibrinolysis are elevated in atherosclerotic plaque. Arterioscler. Thromb. Vasc. Biol. 16:539-545.

10. Ernst, E., and K.L. Resch. 1993. Fibrinogen as a cardiovascular risk factor: a meta-analysis and review of the literature. Ann. Intern. Med. 118:956-963.

11. Hamsten, A., P. Eriksson, F. Karpe, and A. Silveira. 1994. Relationships of thrombosis and fibrinolysis to atherosclerosis. Curr. Opin. Lipidol. 5:382-389.

12. Meade, T.W., S. Mellows, M. Brozovic, G.J. Miller, R.R. Chakrabarti, W.R. North, A.P. Haines, Y. Stirling, J.D. Imeson, and S.G. Thompson. 1986. Haemostatic function and ischaemic heart disease: principal results of the Northwick Park Heart Study. Lancet. 2:533-537.

13. Naski, M.C., and J.A. Shafer. 1991. A kinetic model for the $\alpha$-thrombincatalyzed conversion of plasma levels of fibrinogen to fibrin in the presence of antithrombin III. J. Biol. Chem. 266:13003-13010.

14. McDonagh, J., and M.H. Lee. 1997. How does hyperfibrinogenemia lead to thrombosis? Fibrinolysis \& Proteolysis. 11(Suppl. 1):13-17.

15. Falk, E., and A. Fernandez-Ortiz. 1995. Role of thrombosis in atherosclerosis and its complications. Am. J. Cardiol. 75:3B-11B.

16. Languino, L.R., J. Plescia, A. Duperray, A.A. Brian, E.F. Plow, J.E. Geltosky, and D.C. Altieri. 1993. Fibrinogen mediates leukocyte adhesion to vascular endothelium through an ICAM-1-dependent pathway. Cell. 73:14231434.

17. Katagiri, Y., T. Hiroyama, N. Akamatsu, H. Suzuki, H. Yamazaki, and K. Tanoue. 1995. Involvement of $\alpha \mathrm{v} \beta 3$ integrin in mediating fibrin gel retraction. J. Biol. Chem. 270:1785-1790.

18. Naito, M., H. Nomura, and A. Iguchi. 1996. Migration of cultured vascular smooth muscle cells into non-crosslinked fibrin gels. Thromb. Res. 84:129-136.

19. Languino, L.R., A. Duperray, K.J. Joganic, M. Fornaro, G.B. Thornton, and D.C. Altieri. 1995. Regulation of leukocyte-endothelium interaction and leukocyte transendothelial migration by intercellular adhesion molecule 1-fibrinogen recognition. Proc. Natl. Acad. Sci. USA. 92:1505-1509.

20. Stirk, C.M., A. Kochhar, E.B. Smith, and W.D. Thompson. 1993. Presence of growth-stimulating fibrin degradation products containing fragment $\mathrm{E}$ in human atherosclerotic plaques. Atherosclerosis. 103:159-169.

21. Thompson, W.D., E.B. Smith, C.M. Stirk, and J. Wang. 1993. Fibrin degradation products in growth stimulatory extracts of pathological lesions. Blood Coagul. Fibrinolysis. 4:113-115.

22. Thompson, W.D., E.B. Smith, C.M. Stirk, F.I. Marshall, A.J. Stout, and A. Kocchar. 1992. Angiogenic activity of fibrin degradation products is located in fibrin fragment E. J. Pathol. 168:47-53.

23. Breslow, J.L. 1996. Mouse models of atherosclerosis. Science. 272:685-688.

24. Suh, T.T., K. Holmbäck, N.J. Jensen, C.C. Daugherty, K. Small, D.I. Simon, S. Potter, and J.L. Degen. 1995. Resolution of spontaneous bleeding events but failure of pregnancy in fibrinogen-deficient mice. Genes Dev. 9: 2020-2033.

25. Bugge, T.H., M.J. Flick, C.C. Daugherty, and J.L. Degen. 1995. Plasminogen deficiency causes severe thrombosis but is compatible with development and reproduction. Genes Dev. 9:794-807.

26. Carmeliet, P., L. Schoonjans, L. Kieckens, B. Ream, J. Degen, R. Bronson, R. De Vos, J.J. van den Oord, D. Collen, and R.C. Mulligan. 1994. Physiological consequences of loss of plasminogen activator gene function in mice. Nature. 368:419-424.

27. Nakashima, Y., A.S. Plump, E.W. Raines, J.L. Breslow, and R. Ross. 1994. ApoE-deficient mice develop lesions of all phases of atherosclerosis throughout the arterial tree. Arterioscler. Thromb. 14:133-140.

28. Reddick, R.L., S.H. Zhang, and N. Maeda. 1994. Atherosclerosis in mice lacking apo E. Evaluation of lesional development and progression. Arterioscler. Thromb. 14:141-147.

29. Plump, A.S., J.D. Smith, T. Hayek, K. Aalto-Setala, A. Walsh, J.G. Verstuyft, E.M. Rubin, and J.L. Breslow. 1992. Severe hypercholesterolemia and atherosclerosis in apolipoprotein E-deficient mice created by homologous recombination in ES cells. Cell. 71:343-353.

30. Horiuchi, K., S. Tajima, M. Menju, and A. Yamamoto. 1989. Structure and expression of mouse apolipoprotein E gene. J. Biochem. (Tokyo). 106:98-103.

31. Bugge, T.H., K.W. Kombrinck, M.J. Flick, C.C. Daugherty, M.J. Danton, and J.L. Degen. 1996. Loss of fibrinogen rescues mice from the pleiotropic effects of plasminogen deficiency. Cell. 87:709-719.

32. Paigen, B., A. Morrow, P.A. Holmes, D. Mitchell, and R.A. Williams. 
1987. Quantitative assessment of atherosclerotic lesions in mice. Atherosclerosis. 68:231-240.

33. Lawn, R.M., D.P. Wade, R.E. Hammer, G. Chiesa, J.G. Verstuyft, and E.M. Rubin. 1992. Atherogenesis in transgenic mice expressing human apolipoprotein(a). Nature. 360:670-672.

34. Zhang, S.H., R.L. Reddick, J.A. Piedrahita, and N. Maeda. 1992. Spontaneous hypercholesterolemia and arterial lesions in mice lacking apolipoprotein E. Science. 258:468-471.

35. Ishibashi, S., J.L. Goldstein, M.S. Brown, J. Herz, and D.K. Burns. 1994. Massive xanthomatosis and atherosclerosis in cholesterol-fed low density lipoprotein receptor-negative mice. J. Clin. Invest. 93:1885-1893.

36. Chiesa, G., H.H. Hobbs, M.L. Koschinsky, R.M. Lawn, S.D. Maika, and R.E. Hammer. 1992. Reconstitution of lipoprotein(a) by infusion of human low density lipoprotein into transgenic mice expressing human apolipoprotein(a).J. Biol. Chem. 267:24369-24374.

37. Scanu, A.M., R.M. Lawn, and K. Berg. 1991. Lipoprotein(a) and atherosclerosis. Ann. Intern. Med. 115:209-218.

38. Hajjar, K.A., D. Gavish, J.L. Breslow, and R.L. Nachman. 1989. Lipoprotein(a) modulation of endothelial cell surface fibrinolysis and its potential role in atherosclerosis. Nature. 339:303-305.

39. Harpel, P.C., B.R. Gordon, and T.S. Parker. 1989. Plasmin catalyzes binding of lipoprotein (a) to immobilized fibrinogen and fibrin. Proc. Natl. Acad. Sci. USA. 86:3847-3851.

40. Rouy, D., P. Grailhe, F. Nigon, J. Chapman, and E. Angles-Cano. 1991.
Lipoprotein(a) impairs generation of plasmin by fibrin-bound tissue-type plasminogen activator. In vitro studies in a plasma milieu. Arterioscler. Thromb. 11: 629-638.

41. Xiao, Q., M.J.S. Danton, D.P. Witte, M.C. Kowala, M.T. Valentine, T.H. Bugge, and J.L. Degen. 1997. Plasminogen deficiency accelerates vessel wall disease in mice predisposed to atherosclerosis. Proc. Natl. Acad. Sci. USA. 94:10335-10340.

42. Grainger, D.J., P.R. Kemp, A.C. Liu, R.M. Lawn, and J.C. Metcalfe. 1994. Activation of transforming growth factor- $\beta$ is inhibited in transgenic apolipoprotein(a) mice. Nature. 370:460-462.

43. Grainger, D.J., L. Wakefield, H.W. Bethell, R.W. Farndale, and J.C. Metcalfe. 1995. Release and activation of platelet latent TGF- $\beta$ in blood clots during dissolution with plasmin. Nat. Med. 1:932-937.

44. Odekon, L.E., F. Blasi, and D.B. Rifkin. 1994. Requirement for receptor-bound urokinase in plasmin-dependent cellular conversion of latent TGF- $\beta$ to TGF-ß. J. Cell Physiol. 158:398-407.

45. Moran, C.S., J.H. Campbell, D.L. Simmons, and G.R. Campbell. 1994. Human leukemia inhibitory factor inhibits development of experimental atherosclerosis. Arterioscler. Thromb. 14:1356-1363.

46. Carmeliet, P., L. Moons, V. Ploplis, E. Plow, and D. Collen. 1997. Impaired arterial neointima formation in mice with disruption of the plasminogen gene. J. Clin. Invest. 99:200-208.

47. Lindner, V., J. Fingerle, and M.A. Reidy. 1993. Mouse model of arterial injury. Circ. Res. 73:792-796. 